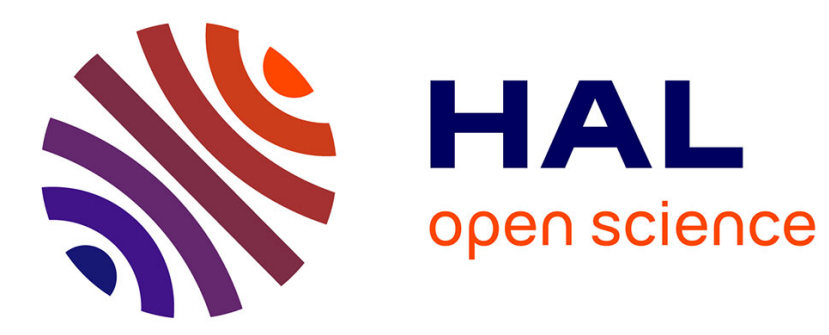

\title{
Thermal expansion of Al3Ce at very low temperatures
}

M. Ribault, Angélique Benoit, J. Flouquet, J. Palleau

\section{To cite this version:}

M. Ribault, Angélique Benoit, J. Flouquet, J. Palleau. Thermal expansion of Al3Ce at very low temperatures. Journal de Physique Lettres, 1979, 40 (16), pp.413-417. 10.1051/jphyslet:019790040016041300 . jpa-00231656

\section{HAL Id: jpa-00231656 https://hal.science/jpa-00231656}

Submitted on 1 Jan 1979

HAL is a multi-disciplinary open access archive for the deposit and dissemination of scientific research documents, whether they are published or not. The documents may come from teaching and research institutions in France or abroad, or from public or private research centers.
L'archive ouverte pluridisciplinaire HAL, est destinée au dépôt et à la diffusion de documents scientifiques de niveau recherche, publiés ou non, émanant des établissements d'enseignement et de recherche français ou étrangers, des laboratoires publics ou privés. 


\title{
Thermal expansion of $\mathrm{Al}_{3} \mathrm{Ce}$ at very low temperatures
}

\author{
M. Ribault, A. Benoit (*) \\ Laboratoire de Physique des Solides (**), Bât. 510, Université Paris-Sud, 91405 Orsay, France
}

J. Flouquet and J. Palleau

Centre de Recherches sur les Très Basses Températures, C.N.R.S., BP 166X, 38042 Grenoble Cedex, France.

(Rę̧u le 26 décembre 1978, révisé le 21 juin 1979, accepté le 27 juin 1979)

\begin{abstract}
Résumé. - En dessous de $1 \mathrm{~K}$ le coefficient de dilatation thermique $\alpha$ de $\mathrm{Al}_{3} \mathrm{Ce}$ est négatif et tend linéairement vers 0 à $0 \mathrm{~K}$. La variation avec la pression de la chaleur spécifique $\gamma T$ déduite de la variation initiale de $\alpha$ est forte : $\partial \gamma / \partial P=0,62 \mathrm{~J} / \mathrm{K}^{2}$ mole kbar. Ces propriétés ne peuvent pas être interprétées dans un modèle d'interaction de Kondo sur des ions isolés mais s'expliquent bien par un comportement de liquide de Fermi (F.L.). Les expériences de magnétostriction montrent clairement les différences existant entre un F.L. ordinaire comme l'hélium trois liquide et un F.L. résultant de l'interaction d'électrons itinérants avec un réseau d'ions magnétiques.
\end{abstract}

Abstract. - Below $1 \mathrm{~K}$ the thermal expansion coefficient $\alpha$ of $\mathrm{Al}_{3} \mathrm{Ce}$ is negative and linearly approaches zero at $0 \mathrm{~K}$. The pressure variation of the specific heat $\gamma T$ deduced from the initial variation of $\alpha$ is very strong :

$$
\partial \gamma / \partial P=0.62 \mathrm{~J} / \mathrm{K}^{2} \text { mole kbar } .
$$

These properties cannot be interpreted with a single ion Kondo effect model but can be interpreted in terms of Fermi liquid (F.L.) behaviour. The magnetostriction experiments clearly show the differences between an ordinary F.L. such as ${ }^{3} \mathrm{He}$ and the F.L. built with a lattice of magnetic ions coupled with and by itinerant electrons.

The abnormal cerium compounds such as $\mathrm{Al}_{2} \mathrm{Ce}$, In ${ }_{3} \mathrm{Ce}, \mathrm{Al}_{3} \mathrm{Ce}$ are characterized by a high value of the coefficient $(\gamma)$ of the linear term in the temperature variation of the specific heat [1]. Whereas the first two above compounds are magnetically well ordered [2] with ordering temperatures of, respectively, $3.8 \mathrm{~K}$ and $10.8 \mathrm{~K}$, the third seems to be in a non magnetic ground state at very low temperatures $[3,4]$ and its $\gamma$ coefficient is one order of magnitude higher than that of the other two [4].

At low temperature the other striking results previously reported for the $\mathrm{Al}_{3} \mathrm{Ce}$ compound are :

i) the $T^{2}$ dependence of the temperature variation of the resistivity up to $200 \mathrm{mK}$ [4],

ii) the temperature variation of the magnetoresistance which is negative down to $0.5 \mathrm{~K}$ and positive below [5],

(*) Present address : Centre de Recherches sur les Très Basses Températures, C.N.R.S., BP 166X, 38042 Grenoble Cedex, France.

(**) Laboratoire associé au C.N.R.S. iii) the abnormal thermal expansion coefficient $(\alpha)$ which changes sign at $0.65 \mathrm{~K}$ and seems to have a negative maximum at the lowest temperature $(300 \mathrm{mK})$ [4].

Below $350 \mathrm{mK}$, the first two measurements lead to a description in term of two band model [4] whereas, in this line, the last one needs low temperature extension. As classical thermodynamic shows that the linear temperature dependence of the specific heat is connected with a corresponding dependence of the thermal expansion, the problems were :

i) the sign and the magnitude of this linear temperature dependence.

ii) the interpolation between the $300 \mathrm{mK}$ minimum and the low temperature linear approach. Since $\mathrm{Al}_{3} \mathrm{Ce}$ appears to be on the border of the magnetic-non magnetic transition a strong pressure effect is suspected in the electronic free energy leading to a high slope for the corresponding derivative such as the thermal expansion. In our opinion, the sign of this variation cannot be predicted. From an experi- 
mental point of view, this observation is the first attempt to directly detect the variation of the thermal expansion over a wide range of temperature starting from a very low temperature.

We have performed thermal expansion experiments on different samples of $\mathrm{Al}_{3} \mathrm{Ce}$ down to $20 \mathrm{mK}$. Longitudinal magnetostriction, up $26 \mathrm{kOe}$, will be discussed but, at present time, only qualitative results are available. Low field transverse magnetostriction measurements were also performed.

1. Experimental approach. - Pressure $(P)$, volume $(V)$, temperature $(T)$, entropy $(S)$, magnetic field $(H)$ and magnetic induction $(B)$ are a set of variables that perfectly defines our physical system. The generalized free energy variation is :

$$
\mathrm{d} G=-S \mathrm{~d} T+V \mathrm{~d} P-B \mathrm{~d} H .
$$

The corresponding Maxwell relations are :

and

$$
\left(\frac{\partial V}{\partial T}\right)_{P, H}=-\left(\frac{\partial S}{\partial P}\right)_{T, H}
$$

$$
\left(\frac{\partial V}{\partial H_{i}}\right)_{P, T}=-\left(\frac{\partial B_{i}}{\partial P}\right)_{H, T}=-4 \pi\left(\frac{\partial M_{i}}{\partial P}\right)_{H, T}
$$

Thermal expansion and magnetostriction studies are very suitable ways of looking at the initial pressure variations of the entropy and the magnetic moment. Notably, we emphasize that this variation is obtained without addenda and without having to deal with the anisotropy effects which are almost always present in a pressure cell.

2. Experimental conditions. - The $\mathrm{Al}_{3} \mathrm{Ce}$ samples have been prepared independently by a vacuum melting of both components in a high frequency furnace followed by an annealing at $1000^{\circ} \mathrm{C}$ for one week. The main problem is the existence of the two parasitic phases of $\mathrm{Al}_{2} \mathrm{Ce}$ and $\mathrm{Al}_{11} \mathrm{Ce}_{3}$. The content of $\mathrm{Al}_{2} \mathrm{Ce}$ has been estimated from X-ray powder patterns. The sample I shows a content of $\mathrm{Al}_{2} \mathrm{Ce}$ corresponding to a ratio $\mathrm{Al}_{2} \mathrm{Ce} / \mathrm{Al}_{3} \mathrm{Ce}$ of $5 \%$ whereas in the sample II the ratio is lower than $5 \%$ and cannot be determined. The content of $\mathrm{Al}_{11} \mathrm{Ce}_{3}$ has been estimated by using magnetization measurements. At $4.2 \mathrm{~K}, \mathrm{Al}_{11} \mathrm{Ce}_{3}$ is in a ferromagnetic like state [6] : the low field magnetization measurements performed on our sample at $4.2 \mathrm{~K}$ agree with a ratio $\mathrm{Al}_{11} \mathrm{Ce}_{3} / \mathrm{Al}_{3} \mathrm{Ce}$ lower than $2 \%$.

In sample II the low temperature susceptibility has been found to be constant from $1 \mathrm{~K}$ to $0.05 \mathrm{~K}$ up to $3 \mathrm{kOe}$ and is equal to $0.038 \mathrm{emu} / \mathrm{mole}$ to be compared with $0.036 \mathrm{emu} / \mathrm{mole}$ at $0.1 \mathrm{~K}$ in [4].

We attribute a measurement to a genuine property of $\mathrm{Al}_{3} \mathrm{Ce}$ when :

- a similar result is obtained for independently prepared samples,
- its order of magnitude is high compared to what is expected from the parasitic phases.

Thermal expansion and magnetostriction results in $\mathrm{Al}_{2} \mathrm{Ce}$ have been published down to $1.5 \mathrm{~K}$ but no results are available at lower temperatures or for the $\mathrm{Al}_{11} \mathrm{Ce}_{3}$ compound. As a first approach, we know that, below $2 \mathrm{~K}$, the specific heat [7] is insensitive with respect to the content of the parasitic phases of $\mathrm{Al}_{11} \mathrm{Ce}_{3}$ and $\mathrm{Al}_{2} \mathrm{Ce}$ and so we think that there is no strong variation of their properties in this temperature range.

Linear expansion $\Delta L / L$ was measured by the usual capacitive method. The cell was made of oxygen free high conductivity copper (O.F.H.C. Copper) the capacity monitored by the sample and the reference capacity were compared using a DT 72 A decade transformer from Electro Scientific Industries. The reference capacity was maintained at $4.2 \mathrm{~K}$ whereas the sample temperature was regulated with a stability better than $10^{-4} \mathrm{~K}$.

The samples are cylinders of $6 \mathrm{~mm}$ diameter with a length of about $9 \mathrm{~mm}$. They were glued onto copper with an epoxy glue either Araldite from CIBA or M.600 from Micromeasurements. The sensitivity of the measurement was $(\Delta L / L)<10^{-9}$. The systematic error due to the estimation of the surfaces is less than $5 \%$ in II and $8 \%$ in I.

In zero field the temperature was measured by a carbon resistor previously calibrated at low temperatures by nuclear orientation [8]. In the magnetostriction experiments, the published magnetoresistance results on the same resistors [8] were used and also a capacitor thermometer CS400 Basic from Lake Shore Cryotronics. At the present time the lack of accuracy of the temperature measurements in a magnetic field prevents any quantitative interpretation of our magnetostriction measurements being made.

3. Experimental results. - 3.1 LINEAR TEMPERATURE DEPENDENCE OF THE THERMAL EXPANSION. Below $200 \mathrm{mK}$, the zero pressure heat capacity has been found by Andres et al. [4] and recently by Lasjaunias et al. [7] to be linear in temperature :

$$
C_{p}=\gamma T \text {. }
$$

Using Maxwell's relation, this must lead to a linear temperature dependence of the thermal expansion. Such a behaviour is observed experimentally here as is shown in figure 1 . We underline the fact that below $300 \mathrm{mK}$ there is excellent agreement between both samples. The magnitude of the thermal expansion is connected to the pressure dependence of $\gamma$ by the relation :

$$
\alpha=\frac{1}{L} \frac{\partial L}{\partial T}=-\frac{1}{3 V}\left(\frac{\partial \gamma}{\partial P}\right) T
$$

where $V$ is the molar volume. The measured value 
is a constant up to $250 \mathrm{mK}$ and is equal to a very strong value $\frac{\partial \gamma}{\partial P}=620 \mathrm{~mJ} / \mathrm{K}^{2}$ mole kbar.

Finally the linear thermal expansion measured in a magnetic field of $3 \mathrm{kOe}$ parallel to the sample axis cannot be distinguished from the zero field measurements. This shows that the low temperature ground state is rather field insensitive.

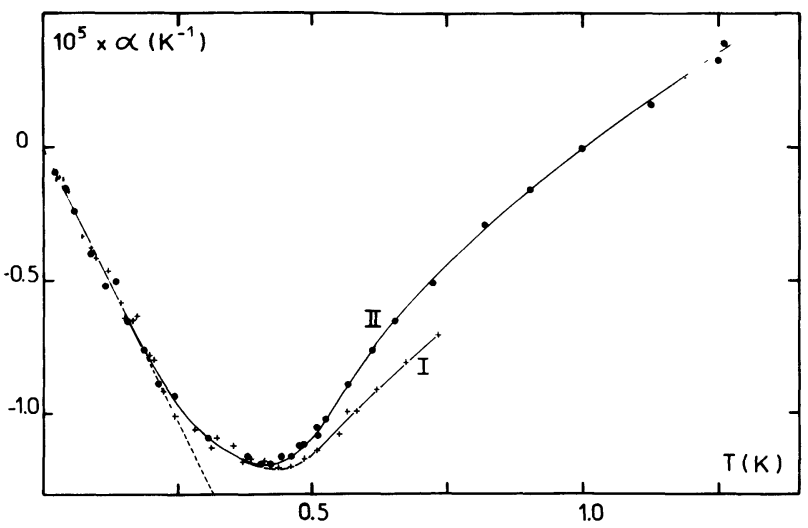

Fig. 1. - Variation of the thermal expansion of $\mathrm{Al}_{3} \mathrm{Ce}$ as a function - of the temperature.

3. 2 High temperature Regime. - From 200 to $350 \mathrm{mK}$, the thermal expansion saturates slowly reaching $-1.2 \times 10^{-5} \mathrm{~K}^{-1}$. At higher temperatures, $\alpha$ increases and the two samples depart from each other ; the zero value is reached at $1.25 \mathrm{~K}$ for sample $\mathrm{I}$ and $1 \mathrm{~K}$ for sample II.

The main result of these measurements is the linear approach to zero from the negative maximum of $\alpha$. The positive sign of $\alpha$ above $1.3 \mathrm{~K}$ is in agreement with the decrease of the specific heat under pressure observed in the same range [9]. The temperature variation of $\alpha$ flattens above $2 \mathrm{~K}$ reaching $1.17 \times 10^{-5}$ at $4 \mathrm{~K}$ (sample II).

Comparing with the results of Andres et al. we note that in our case :

i) the temperature of the extreme and zero values of $\alpha$ are shifted to higher values,

ii) the higher positive value of $\alpha$ is not accurately detected,

iii) the $\alpha$ values at the extrema are smaller.

The sample of Andres et al. seems to have a much higher value of $\partial \gamma / \partial P$ by a factor of at least $40 \%$ this has to be connected with the much higher value of $\gamma: 1.6 \mathrm{~J} / \mathrm{mole}^{2}$ [4] to be compared with $1.4 \mathrm{~J} / \mathrm{mole} \mathrm{K}^{2}$ [7].

These differences cannot be due to temperature calibration and are larger than experimental uncertainties : we think they are due to differences between samples. Such a result is obvious owing to the great pressure and impurity sensitivity of this material (see ref. [10]).
4. Magnetic field dependence. - From previous nuclear orientation experiments we know that, without any regulation, the lowest temperature of our dilution refrigerator increases by a few $\mathrm{mK}$ when the magnetic field increases up to a value of $70 \mathrm{kOe}$ and is almost field independent for fields of a few kOe. So, at the lowest temperature of our refrigerator $(20 \mathrm{mK})$ the thermal expansion being low, the detected variations are purely magnetically induced. This is not necessarily the case for higher temperatures where the lack of sensitivity or accuracy of our temperature probes and the great thermal expansion (except at $1 \mathrm{~K})$ can induce hybridization between the thermal and the magnetic effect. We have checked that the results are not qualitatively modified by varying temperature in the uncertainty limit.

At $20 \mathrm{mK}$, both in longitudinal and tranverse magnetic fields, $\Delta L / L$ from 0 to $1 \mathrm{kOe}$ is lower than $2 \times 10^{-9}$. When the applied magnetic field is increased, the magnetostriction appears with a large irreversible part which is still important up to $26 \mathrm{kOe}$. Thermal variations cannot explain such a result. We must consider the existence of magnetically ordered phases. Table I reports the longitudinal magnetostriction measured at different temperatures in a magnetic field of $26 \mathrm{kOe}$ for the sample II as well as the strength $\beta$ of any $H^{2}$ dependence.

Table I. - Summary of the magnetostriction experiments.

$\begin{array}{ccccc}T \text { in K } & 11 & 4.2 & 1 & 0.2 \\ \frac{L-L_{0}}{L_{0}} \times 10^{7} & 5.2 & 13 & 20 & 0.2 \\ \beta \times 10^{9} & 0.7 & 1.8 & 2.6 & -\end{array}$

At $4.2 \mathrm{~K}$, the variation is reversible : at $1 \mathrm{~K}$ the irreversible part reaches its higher value of $0.9 \times 10^{-7}$ for $H=1.5 \mathrm{kOe}$ and is less than $0.3 \times 10^{-7}$ above $4 \mathrm{kOe}$. At $0.2 \mathrm{~K}$, the irreversible higher value is $1.4 \times 10^{-7}$ for $H=3 \mathrm{kOe}$ and the irreversible contribution is less than $0.3 \times 10^{-7}$ above $9 \mathrm{kOe}$. A quadratic law in magnetic field is well observed at $11 \mathrm{~K}$, at $4.2 \mathrm{~K}$ this law is obtained for $H>9 \mathrm{kOe}$ and at $1 \mathrm{~K}$ for $H>13 \mathrm{kOe}$. At $200 \mathrm{mK}$ it cannot be observed at all for $H$ up to $26 \mathrm{kOe}$. We must underline the fact that, at low temperatures, the magnetostriction is low and that the amplitude of its irreversible part is certainly one way of measuring the content of the two parasitic phases of $\mathrm{Al}_{11} \mathrm{Ce}_{3}$ and $\mathrm{Al}_{2} \mathrm{Ce}$. For the reversible part, we recall that for $\mathrm{Al}_{2} \mathrm{Ce}$, at $4.2 \mathrm{~K}$ just above its ordering temperature ; in $26 \mathrm{kOe}, \Delta L / L \sim 0.5 \times 10^{-4}$ [11]. So $4 \%$ of $\mathrm{Al}_{2} \mathrm{Ce}$ in $\mathrm{Al}_{3} \mathrm{Ce}$ (which is the sensitivity of our X-ray powder pattern measurements) would agree with a longitudinal magnetostriction of the whole sample 
of $20 \times 10^{-7}$ to be compared with $13 \times 10^{-7}$ in sample II. The same qualitative argument can explain the irreversible part of the magnetostriction above $4 \mathrm{kOe}$ at $1 \mathrm{~K}$. The departure from a $H^{2}$ law at low fields and the low field irreversibilities at $1 \mathrm{~K}$ may be connected to $\mathrm{Al}_{11} \mathrm{Ce}_{3}$ but, for this compound, no results are presently available.

5. Discussion. - In $\mathrm{Al}_{3} \mathrm{Ce}$, the cerium ions appear to be in a trivalent valency state [12] with the corresponding localized moment at high temperatures The reported low temperature properties will be interpreted in terms of many body correlations between the well defined localized moment and the conduction electrons. Successively the Kondo like coupling without and with coherence among the cerium ions will be analysed. Strong evidence will be presented for the importance of coherence for the low temperature properties. At low temperatures, the strong variation of $(\mathrm{d} \gamma / \mathrm{d} P)$ is in agreement with the predictions of the phenomenological model developed by Benoit et al. [13]. In this model $\mathrm{Al}_{3} \mathrm{Ce}$ is situated at the non magnetic border of the magneticnon magnetic transition. This special position can explain the magnitude of $(\mathrm{d} \gamma / \mathrm{d} P)$ but the sign of the variation cannot be determined. In all the dilute alloys which present a Kondo anomaly the coupling increases under pressure ; by analogy it has been assumed that there is an increase of $T_{\mathrm{K}}$ and a corresponding decrease of $\gamma$ under pressure ; this appears now to be wrong. And this clearly shows that the Kondo approach to this problem is only a way of expressing the coupling between the magnetic ions and the conduction electrons and that it may be confusing to use the expression Kondo temperature to express this correlation.

At temperatures higher than $1.3 \mathrm{~K}$, the positive sign of $(\partial V / \partial T)$ and the corresponding variations of magnetization and specific heat with pressure are consistent with the usual Kondo behaviour of a single ion : above $1.3 \mathrm{~K}$ the ions can be regarded as being isolated and in interaction with the Fermi sea. Below, the coherence develops to build the many body state leading to the low temperature properties.

In an ideal Fermi gas, a positive value of the low temperature thermal expansion is expected. Brueckner et al. [14] have established that in the case of a Fermi liquid the effective mass of the fermions is increasing under pressure and so, if the gradient of this variation is high enough, the low temperature thermal expansion may be negative [15].

As explained in this paper, this can be understood as an effect of the condensation of the quasiparticules in the state of moment order :: the exclusion principle increases the repulsion and so the Fermi liquid expands. In the case of ${ }^{3} \mathrm{He}$, which was the main interest of Brueckner, the zero point motion reduces the attraction and so enhances this low temperature effect ; in our case, we have no such convergence and so the effect is lower. But in both cases the results are qualitatively the same : the thermal expansion which is positive becomes negative, reaches an extreme value and approaches $0 \mathrm{~K}$ linearly.

In a Fermi liquid (F.L.), the magnetic susceptibility $(\chi)$ and the specific heat $(C)$ are not directly related as for an ideal Fermi gas (F.G.). As a first consequence, the magnetic susceptibility may be enhanced as compared with the magnetic susceptibility of a F.G. having the same specific heat, another consequence is that the pressure variation of the specific heat and of the magnetic susceptibility are not necessarily the same. In the liquid ${ }^{3} \mathrm{He}$ they are almost the same [16], but not in $\mathrm{Al}_{3} \mathrm{Ce}$. Let us explain this statement which is deduced from our measurements.

When the ratio $\chi / C$ remains a constant under pressure the ratio $(\partial \chi / \partial P) /(\partial C / \partial P)$ and so the ratio of the magnetostriction to the thermal expansion must be a constant. This ratio is $(12 / \pi)\left(\mu_{\mathrm{B}}^{*} / k_{\mathrm{B}}\right)^{2}$ where $\mu_{\mathrm{B}}^{*}$ includes the $\chi$ enhancement : the thermal expansion from 0 to $0.2 \mathrm{~K}$ must be equal to the magnetostriction from 0 to $1 \mathrm{kOe}$. In $\mathrm{Al}_{3} \mathrm{Ce}$ the low temperature $(20 \mathrm{mK})$ magnetostriction from 0 to $1 \mathrm{kOe}$ is, at least, two orders of magnitude lower than the thermal expansion from $0 \mathrm{~K}$ to $0.2 \mathrm{~K}$. To explain this result we have to remember that, whereas ${ }^{3} \mathrm{He}$ has a spin magnetic moment, in $\mathrm{Al}_{3} \mathrm{Ce}$ we may have to consider an induced moment and so the magnetic interaction cannot be reduced to the polarization of an effective magneton in the applied field. The effect of the magnetic field is still connected with the individual coupling between the electrons and magnetic ions. Another way of expressing this effect is to say that in the many body expression of the susceptibility the spin dependence of the interaction is, in $\mathrm{Al}_{3} \mathrm{Ce}$, strongly pressure dependent and that the effect of its variation nearly cancels the effect of the variation of the effective mass. The magnetic field range is not 0 to $1 \mathrm{kOe}$ but 0 to a few hundreds of kOe. The experimental results which justify this statement are :

i) the very low value of the magnetostriction,

ii) the magnetic field independence of the thermal expansion,

iii) the very weak [4] variation of the magnetic susceptibility up to $3 \mathrm{kOe}$.

The parasitic phases and the lack of information about their low temperature magnetostriction do not allow any quantitative discussion to be made concerning the high magnetic field measurements.

As a conclusion, we can say that if the comparison between thermal properties of $\mathrm{Al}_{3} \mathrm{Ce}$ and ${ }^{3} \mathrm{He}$ are very stimulating the discrepancy appears to be large when the magnetic properties are considered. The way in which the Fermi liquid states are built strongly disturbs the analogies. 
Acknowledgments. - The authors would like to thank Dr. I. A. Campbell and M. J. Sanchez for their interest in the thermal expansion measurements. We are greatly indebted for helpful discussions, to Dr. B. Coqblin, Prof. J. Friedel, Dr. J. C. Lasjaunias, Prof. P. Nozières, Dr. R. Maynard, Dr. M. Papoular, Dr. J. Peyrard and Dr. R. Rammal.

\section{References}

[1] Berton, A., Chaussy, J., Chouteau, G., Cornut, B., Flouquet, J., Odin, J., Palleau, J., Peyrard, J. and Tournier, R., J. Physique Colloq. 40 (1979) C5-326.

[2] Benoit, A., Flouguet, J., Ribault, M., J. Physique Lett. 39 (1978) L-63.

[3] Benoit, A., Flouquet, J., Ribault, M., Chapellier, M., Solid State Commun. 26 (1978) 319.

[4] Andres, K., Graebner, J. E. and Ott, H., Phys. Rev. Lett. 35 (1975) 1779.

[5] Edelstein, A. S., Tranchita, G. J., Mac Masters, O. D. and Gschneidner Jr., K. A., Solid State Commun. 15 (1974) 81.

[6] Chouteau, G., Flouguet, J., Keradec, J. P., Peyrard, J., Tournier, R., J. Physique Lett. 39 (1978) L-461.

[7] Lasjaunias, J. C. and Peyrard, J., Private communication.

[8] Sanchez, J., Benoit, A. and Flouguet, J., Rev. Sci. Instrum. 48 (1977) 1090.

[9] Berton, A., Chaussy, J., Cornut, B., Chouteau, G., Peyrard, J., Tournier, R., Proceedings Conf. on Valence Instabilities ed. by R. D. Parks (Plenum Press), 1976, p. 471.
[10] Edelstein, A. S., Majewski, R. E. and Bluvitr, T. H., in Valence Instabilities (1976) 115.

[11] Croft, M., Zoric, I. and Parks, R. D., Phys. Rev. B 18 (1978) 345.

[12] Mader, K. H. and Swift, W. M., J. Phys. Chem. Solids 29 (1968) 1759.

[13] Benoit, A., Flouquet, J., Ribault, M., Flouguet, F., Chouteau, G., Tournier, R., J. Physique Lett. 39 (1978) L-94.

[14] Brueckner, K. A. and Gammel, J. C., Phys. Rev. 109 (1958) 1023.

[15] Brueckner, K. A. and Atkins, K. R., Phys. Rev. Lett. 1 (1958) 315.

[16] Boghosian, C., Meyer, H. and Rives, J. E., Phys. Rev. 146 (1966) 110.

[17] See Wheatley, J. C., The Helium Liquids (Academic Press) 1975, p. 241. 